\title{
Correction to: Characterization of MX-80 bentonite and its sorption of radionickel in the presence of humic and fulvic acids
}

\author{
Jun $\mathrm{Hu}^{1,2} \cdot \mathrm{Di} \mathrm{Xu}^{2} \cdot$ Lei Chen $^{3} \cdot$ Xiangke Wang $^{2}$
}

Published online: 4 March 2020

๑) Akadémiai Kiadó, Budapest, Hungary 2020

\section{Correction to: \\ Journal of Radioanalytical and Nuclear Chemistry, Vol. 279, No.3 (2009) 701-708 \\ https://doi.org/10.1007/s10967-007-7252-6}

The original publication of the article includes mistakes on instrument types of FTIR and XRD characterization in page 702. The corrected instrument types of FTIR and XRD characterization were shown in this correction. These corrections do not affect any of the discussion or conclusion of the paper.

The sample of bentonite was characterized by using Fourier Transform Infrared sorption (FTIR) (Bruker EQUINOX55) in pressed $\mathrm{KBr}$ pellets.

The original article can be found online at https://doi.org/10.1007/ s10967-007-7252-6.

Xiangke Wang

xkwang@ipp.ac.cn

1 School of Nuclear Science and Engineering, North China Electric Power University, Beijing 100080, People's Republic of China

2 Institute of Plasma Physics, Chinese Academy of Sciences, P.O. Box 1126, Hefei 230031, People's Republic of China

3 School of Chemical Engineering, Shandong University of Technology, Zibo 255049, People's Republic of China
The XRD pattern of the montmorillonite crystal was recorded on a D/Max-2400 Rigaku diffractometer.

Publisher's Note Springer Nature remains neutral with regard to jurisdictional claims in published maps and institutional affiliations. 